\title{
HUBUNGAN PENGETAHUAN WUS TENTANG KEBERSIHAN AREA GENITAL DENGAN \\ KEJADIAN KEPUTIHAN DI WILAYAH KERJA PUSKESMAS KECAMATAN \\ MANISRENGGO KLATEN
}

\author{
Hernandia Happy Safitri ${ }^{1}$, Wiwin Lismidianti ${ }^{2}$, Ika Hermawati $C^{3}$ \\ ${ }^{1,2}$ Program Studi Keperawatan UGM, ${ }^{3} \mathrm{~S} 1 \mathrm{IImu}$ Keperawatan STIKes Guna \\ Bangsa Yogyakarta
}

\begin{abstract}
Background: Leucorrhoea is a disease of the reproductive system that suffered by many women most of the world. One of the causes leucorrhea is a lack of knowledge keep cleaning the genital area. Many factors affecting by the lack of knowledge, one of which is the lack of information. Data on the public health center Manirenggo Klatenin 2013, 153 women of reproductive age on Ngemplak Seneng Village District of Klaten Manis renggo most experience vaginal discharge.

Aim: The aim of this research is to know the correlation between knowledge about hygiene the genital area WUS with leucorrhoea, to find out knowledge about hygiene WUS genital area, to find out how much the incidence of leucorrhoea in public health center district Manisrenggo Klaten.

Method: This was on non experimental research with also correlation descriptive research that using The cross-sectional design. This research uses purposive sampling with 60 respondents. Analyzed using univariate, bivariate analysis with the Chi-Square test and contingency coefficient test. The research was conducted in public health center district Manisrenggo, Klaten, Central Java, in April until May 2014.

Result: Percentage Women of Reproductive Age which has a high knowledge is $(56.7 \%)$ or about 34 respondents. 26 respondents had low knowledge and 7 (11.7\%) of them experienced a leucorrhoea. Parametric test contingency correlation coefficient to determine the relationship of knowledge Women of Reproductive Age about hygiene the genital area with a leucorrhoea incident obtained $p$-value 0.001 . Having interpreted $C=0,384$ shows a fairly close relationship.

Conclution: There was correlation between knowledge Women of Reproductive Age about hygiene the genital area with a leucorrhea incident. Knowledge of Women of Reproductive Age about hygiene the genital area is in the high category a number of 34 with a percentage of $56.7 \%$, and the incidence of leucorrhoea in public helath center district Manisrenggo Klaten a number of 7 with a percentage of $11.7 \%$.
\end{abstract}

Keywords: Knowlegde of hygiene the genital area, Women of Reproductive Age, leucorrhoea incident.

\section{PENDAHULUAN}

Kesehatan reproduksi menurut WHO adalah suatu keadaan fisik, mental dan sosial yang utuh, bukan hanya bebas dari penyakit atau kecacatan dalam segala aspek yang berhubungan dengan sistem reproduksi, fungsi serta prosesnya. (Widiyastuti, dkk., 2009)

Pada diri seorang wanita di masa reproduksi biasanya mengalami beberapa gejala psikologik yang negatif atau gejala fisik. Sifat gejalanya bervariasi dan cenderung memburuk ketika saat-saat menjelang dan selama terjadinya proses perdarahan haid pada tubuhnya, Keadaan ini tidak selalu terjadi pada setiap siklus haidnya dan intensitasnya pun tidak sama. Beberapa wanita ada juga yang mengalami gejala alam perasaan dan fisik yang berat, salah satunya adalah 
menyebabkan terjadinya keputihan (Hendrik, 2006).

Keputihan di definisikan sebagai cairan dari kelamin perempuan (vagina) yang berlebihan selain air kencing atau darah. Sifatnya bisa Fisiologis dan Patologis (Indriatmi, 2007).

Berdasarkan dari uraian peneliti tertarik untuk melakukan penelitian tentang hubungan pengetahuan WUS tentang kebersihan area genital dengan kejadian keputihan di wilayah Puskesmas Manisrenggo Klaten.

\section{METODE PENELITIAN}

\section{A. Jenis Penelitian}

Jenis penelitian ini adalah studi korelasi (hubungan) dengan menggunakan desain penelitian cross sectional (meneliti pada satu waktu). Jenis dan desain penelitin ini digunakan untuk menghubungkan antara pengetahuan WUS tentang kebersihan area genital dengan kejadian keputihan.

\section{B. Populasi dan Sampel}

Populasi dalam penelitian ini adalah semua WUS usia 20-45 ada di Dusun III Desa Ngemplak Seneng Kecamatan Manisrenggo. Berdasarkan hasil studi pendahuluan yang telah dilakukan didapatkan data ada 153 WUS. Setelah dilakukan perhitungan ada 60 WUS yang menjadi responden.

Dalam penelitian ini, responden yang dijadikan sampel penelitian memiliki kriteria inklusi dan ekslusi sebagai berikut :

Kriteria Inklusi :
a. WUS yang bersedia menjadi responden.
b. WUS dengan rentang usia 20-45 tahun.
Kriteria Eksklusi :
a. WUS yang sedang hamil atau sedang dalam masa nifas.
$b$. WUS yang sedang dalam fase Pre- Menstrual Syndrome.
c. WUS yang mengalami penyakit reproduksi tertentu.

\section{Variabel Penelitian}

1. Variabel bebas dalam penelitian ini adalah pengetahuan WUS tentang kebersihan area genital. Sedangkan variabel terikatnya adalah kejadian keputihan.

2. Variabel pengganggu

Faktor-faktor lain yang menyebabkan kejadian keputihan seperti ketidakseimbangan hormon, gejala suatu penyakit dll. merupakan variabel pengganggu yang tidak dapat dikendalikan oleh peneliti.

\section{Teknik pengumpulan data}

Pengumpulan data dilakukan oleh peneliti sendiri, data primer pada penelitian ini dikumpulkan dengan pendataan langsung kepada tiap responden di Desa yang akan dijadikan penelitian yaitu Dusun III Desa Ngemplak Seneng Kecamatan Manisrenggo Klaten . Selanjutnya responden diminta menandatangani informed consent dan dilanjutkan mengisi kuesioner.

\section{E. Instrumen Penelitian}

Instrumen yang digunakan dalam penelitian ini adalah kuesioner. Kuesioner pengetahuan perawatan area genital berjumlah 20 butir pernyataan. sedangkan untuk kuesioner tanda dan gejala infeksi ada 14 butir pertanyaan.

\section{F. Pengolahan dan Analisa Data}
1. Analisis Univariat (Analisis Deskriptif)

Analisa hanya menghasilkan distribusi dan persentase dari tiap variabel. Tujuannya untuk menjelaskan atau mendeskripsikan karakteristik masing-masing variabel yang diteliti (Notoatmodjo,2012).

2. Analisis Bivariat

Analisa bivariat dilakukan terhadap dua variabel yang diduga berhubungan atau berkorelasi (Notoatmodjo,2012). Data yang diperoleh dilakukan analisa secara statistik dengan menggunakan Uji Chi-Square dan untuk mengetahui 
keeratan hubungan menggunakan Uji Koefisien Kontingensi.

\section{HASIL DAN PEMBAHASAN}

\section{A. Hasil Penelitian}

1. Karakteristik responden

a. Umur responden

\begin{tabular}{ccc}
$\begin{array}{c}\text { Tabel 4. Distribusi frekuensi umur } \\
\text { WUS di wilayah kerja Puskesmas } \\
\text { Manisrenggo Klaten }(\mathbf{n}=60)\end{array}$ \\
\hline $\begin{array}{c}\text { Kategori } \\
\text { umur }\end{array}$ & Jumlah & $\begin{array}{c}\text { Persent } \\
\text { ase } \%\end{array}$ \\
\hline $20-29$ & 30 & $50 \%$ \\
\hline $30-40$ & 20 & $33,3 \%$ \\
\hline $40-45$ & 10 & $16,7 \%$ \\
\hline Total & 60 & 100 \\
\hline
\end{tabular}

Sumber data primer (2014)

Pada tabel 4 Menunjukkan bahwa : mayoritas responden adalah kategori umur 20-29 tahun sejumlah 30 orang dengan persentase $50 \%$. Sedangkan minoritas responden ada pada kategori umur 40-45 sejumlah 10 orang dengan persentase $16,7 \%$.

2. Analisa Univariat
a. Pengetahuan
WUS Tentang Kebersihan Area Genital

Tabel 5. Distribusi frekuensi pengetahuan WUS tentang kebersihan area genital $(n=60)$

\begin{tabular}{ccc}
\hline $\begin{array}{c}\text { Pengetahuan } \\
\text { WUS tentang } \\
\text { kebersihan area } \\
\text { genital }\end{array}$ & Jumlah & $\begin{array}{c}\text { Persentase } \\
(\%)\end{array}$ \\
\hline Rendah & 26 & $43,3 \%$ \\
Tinggi & 34 & $56,7 \%$ \\
\hline Total & 60 & $100 \%$
\end{tabular}

Sumber data primer (2014)
Pada tabel 5. Diketahui bahwa : pengetahuan WUS tentang kebersihan area genital mayoritas pada kategori tinggi berjumlah 34 responden dengan persentase $56,7 \%$.

Menurut Notoatmodjo (2012), Pengetahuan adalah merupakan hasil 'tahu' dan terjadi setelah orang mengadakan pengindraan terhadap suatu objek tertentu. Hal ini menunjukkan bahwa WUS sudah mampu memahami tentang pengetahuan kebersihan area genital dengan baik. Hal ini dibuktikan dengan hasil penelitian yaitu sebanyak 34 responden memiliki pengetahuan tinggi dengan persentase $56,7 \%$.

Hal ini berbeda dengan penelitian yang dilakukan oleh Suciati (2013) yang menyatakan dari 60 WUS di Puskesmas Miri Sragen memiliki tingkat pengetahuan cukup mengenai pengetahuan keputihan yaitu sejumlah 36 responden dengan persentase $60 \%$.

Hasil analisis dari beberapa teori diatas dapat disimpulkan bahwa pengetahuan tentang kebersihan atau perawatan area genital sangat penting bagi kesehatan organ kewanitaan. Pengetahuan yang baik didapatkan dari informasi yang baik serta faktor-faktor lain yang mempengaruhi penerimaan informasi sebagai dasar pengetahuan.
b. Kejadian Keputihan

Tabel 6. Distribusi kejadian keputihan di wilayah kerja Puskesmas Manisrenggo Klaten $(n=60)$

Kejadian Jumlah Persentase

keputihan

\begin{tabular}{ccc}
\hline Tidak & 53 & $88,3 \%$ \\
Ya & 7 & $11,7 \%$ \\
\hline Total & 60 & $100 \%$ \\
\hline
\end{tabular}

Sumber data primer (2014)

Dari tabel 6. Menunjukkan bahwa: kejadian keputihan di wilayah kerja Puskesmas Manisrenggo Klaten sebanyak 7 responden dengan persentase $11,7 \%$. 
Tabel 7. Distribusi frekuensi insidensi keputihan di wilayah kerja Manisrenggo Klaten $(n=60)$

\begin{tabular}{ccc}
\hline $\begin{array}{c}\text { Frekuensi } \\
\text { insidensi } \\
\text { keputihan }\end{array}$ & Jumlah & $\begin{array}{c}\text { Prosentase } \\
(\%)\end{array}$ \\
\hline $1 \mathrm{x}$ & 17 & $28,33 \%$ \\
$2 \mathrm{x}$ & 9 & $15 \%$ \\
$3 \mathrm{x}$ & 10 & $16,67 \%$ \\
$4 \mathrm{x}$ & 24 & $40 \%$ \\
\hline Total & 60 & $100 \%$ \\
\hline
\end{tabular}

Sumber data primer (2014)

Seperti pada tabel 7. data yang diperoleh peneliti yaitu mayoritas responden mengalami frekuensi insidensi keputihan sebanyak $4 \mathrm{x}$ berjumlah 24 responden dengan persentase $40 \%$. Sedangkan minoritas responden mengalami insidensi keputihan sebanyak $2 \mathrm{x}$ berjumlah 9 responden dengan persentase $15 \%$.

Dalam penelitian ini, hanya 7 responden saja yang terindikasi mengalami kejadian keputihan. Merekalah yang memenuhi kriteria untuk dinilai mengalami kejadian keputihan sesuai dengan kriteria yang sudah ditentukan peneliti.

Sesuai dengan pengertian keputihan yang disampaikan oleh Aulia (2012) keputihan adalah keluarnya cairan berlebihan dari liang senggama (vagina) yang terkadang disertai rasa gatal, nyeri, rasa terbakar di bibir kemaluan, kerap disertai bau busuk, dan menimbulkan rasa nyeri sewaktu buang air kecil atau bersenggama. Peneliti telah menentukan kriteria yang memenuhi bahwa seseorang mengalami kejadian keputihan adalah apabila mengalami tanda dan gejala seperti yang telah disebutkan.

Namun demikian, semua responden pernah mengalami keputihan yang tidak masuk dalam item-item pernyataan yang memenuhi syarat penilaian keputihan sesuai dengan standar yang ditentukan peneliti.

Data yang diperoleh peneliti yaitu minoritas responden mengalami insidensi keputihan sebanyak 2x berjumlah 9 responden dengan persentase $15 \%$. Lalu mayoritas responden mengalami insidensi keputihan sebanyak $4 x$ berjumlah 24 responden dengan persentase $40 \%$.

3. Analisa bivariat

a. Hubungan pengetahuan WUS tentang kebersihan area genital dengan kejadian keputihan.

Tabel 8. Hubungan pengetahuan WUS tentang kebersihan area genital dengan kejadian keputihan di wilayah kerja Puskesmas Manisrenggo Klaten $(n=60)$

\begin{tabular}{|c|c|c|c|}
\hline & & Keputihan & \multirow{2}{*}{$\begin{array}{l}\mathrm{P} \\
\text { value }\end{array}$} \\
\hline & & $\begin{array}{lll}\text { Tidak } & \mathrm{Ya}_{\mathrm{a}} & \text { Total } \\
\end{array}$ & \\
\hline \multirow{6}{*}{ Pengetahuan } & Count & $\begin{array}{ll}19 & 7\end{array}$ & 0,001 \\
\hline & $\%$ of & $31,7 \quad 11,7 \% \quad 43,3 \%$ & \\
\hline & Total & $\%$ & \\
\hline & Count & 34 & \\
\hline & $\%$ of & $0 \% \quad 56,7 \%$ & \\
\hline & Total & $\%$ & \\
\hline \multirow[t]{3}{*}{ total } & Count & 53 & \\
\hline & $\%$ of & $88,3 \% \quad 11,7 \% \quad 100 \%$ & \\
\hline & Total & & \\
\hline
\end{tabular}

Tabel 8. menunjukkan bahwa: responden yang memiliki pengetahuan tentang kebersihan area genital tinggi yaitu 34 responden dengan persentase $56,7 \%$ tidak mengalami keputihan. Sebaliknya responden yang memiliki pengetahuan tentang kebersihan area genital rendah yaitu 26 responden, 7 responden mengalami kejadian keputihan dengan persentase $11,7 \%$. Lalu dapat pula disimpulkan ada hubungan yang signifikan antara pengetahuan WUS tentang kebersihan area genital dengan kejadian keputihan ( $P$ value 0,001$)$.

Hasil yang didapat setelah dilakukan pengolahan data adalah adanya hubungan yang signifikan antara pengetahuan kebersihan area genital dengan kejadian keputihan ( $p$ value $0,001)$. Untuk lebih membuktikan adanya hubungan yang erat peneliti menggunakan interpretasi nilai $C$ sebagai rujukan nilai signifikan keeratan hubungan. Dimana didapatkan hasil adanya hubungan yang cukup erat antara 
pengetahuan kebersihan area genital dengan kejadian keputihan degan nilai $\mathrm{C}=0,384$. Hal ini menambahkan kepercayaan terhadap penelitian bahwa selain adanya hubungan, penelitian ini mempunyai keeratan yang cukup.

\section{KESIMPULAN DAN SARAN}

\section{A. Kesimpulan}

Dari hasil dan pembahasan penelitian yang diuraikan pada bab sebelumnya dapat disimpulkan :

1. Ada hubungan yang signifikan antara pengetahuan WUS tentang kebersihan area genital dengan kejadian keputihan dengan hasil $P$ value 0,001 .

2. Pengetahuan WUS tentang kebersihan area genital ada pada kategori tinggi $(56,7 \%)$.

3. Insidensi keputihan di wilayah kerja Puskesmas Manisrenggo Klaten sebanyak $(11,7 \%)$.

\section{B. Saran}

1. Kepada STIKes Guna Bangsa Yogyakarta untuk semakin meningkatkan pengetahuan peserta didik tentang kesehatan reproduksi khususnya perawatan area genital sehingga dapat meningkatkan penerapannya dalam asuhan keperawatan.

2. Untuk Puskesmas Kecamatan Manisrenggo perlu adanya upaya peningkatan pengetahuan WUS tentang kesehatan reproduksi yang benar secara rutin dengan cara penyuluhan, konseling dan memberikan pemeriksaan terkait masalah kesehatan reproduksi sebagai upaya deteksi dini penyakit kesehatan reproduksi.

\section{DAFTAR PUSTAKA}

Anolis, A.2011. 17 Penyakit wanita yang paling mematikan.Yogyakarta: Buana Pustaka.

Aulia, 2012. Serangan penyakit-penyakit khas wanita paling sering terjadi.Yogyakarta: Buku Biru.
Arikunto, S. 2000. Prosedur Penelitian; Suatu PendekatanPraktek Edisi Ke 3. Jakarta: Rineke Cipta.

Ayuningtyas, 2011. Hubungan antara pengetahuan dan perilaku menjagakebersihan genetalia eksterna dengan kejadian keputihan padasiswa SMA Negeri 4 Semarang. Skripsi.

Bahari, H. 2012. Cara Mudah Atasi Keputihan. Yogyakarta: Buku Biru.

BKKBN 2008. Data Penduduk sasaran program pembangunan kesehatan2011-2014. Jakarta: Pusat data dan Informasi KementrianKesehatan Indonesia.

Dahlan, M. 2010. Besar Sampel dan Cara PengambilanSampel dalam Penelitian Kedokteran dan Kesehatan. Edisi 3.Jakarta : Salemba Medika.

Dahlan, M. 2011. Statistik untuk Kedokteran dan Kesehatan:,Bivariat, dan Multivariat. Edisi 5. Jakarta : Salemba Medika.

Dharma, K. (2011). Metodologi penelitian keperawatan (pedomanmelaksanakan dan menerapkan hasil penelitian). Jakarta : TIM.

Global Alliance Indonesia. (20030. Tanya jawab seputar kesehatanreproduksi : buku pegangan promosi kesehatan pekerja. Jakarta :Global Alliance for Workers and Communities.

Fadilla, dkk. 2014. Pengetahuan Ibu tentang keputihan di Kota Manado.Journal.

Hendrik,H. 2006. Problema Haid (Tinjauan Syariat Islam dan Medis). Solo: Tiga Serangkai.

Indriatmi, W. 2007.Infeksi Menular Seksual. Jakarta: Fakultas Kedokteran Universitas Indonesia. 
Kozier, B., dkk. 2004. Fundamental of nursing : concepts, process, and practice. California : Addison Wesley.

Manuaba, I. G. B, 2010, IImu kebidanan, Penyakit Kandungan dan KB,EGC, Jakarta.

Notoatmodjo, S.2003.IImu kesehatan masyarakat prinsip - prinsip dasar. Jakarta: PT.Rineka Cipta.

Notoatmodjo, S. 2007. Promosi kesehatan dan ilmu perilaku. Jakarta : PT.Rineka Cipta.

Notoatmodjo, S. 2010. Metodologi penelitian kesehatan. Jakarta: PT Rineka Cipta.

Notoatmodjo, S. 2012. Pendidikan dan Perilaku Kesehatan. Jakarta:PT Rineka Cipta.

Nursalam \& S Pariani. 2000. Metodologi Riset Keperawatan. CV Sagung Seto. Jakarta.
Sembiring, M. 2012. Hubungan Perilaku Kebersihan Genetalia Remaja Putri Terhadap Munculnya Tanda dan Gejala Infeksi Sistem Reproduksi. Skripsi.

Suciati (2013), dengan judul "Tingkat pengetahuan wanita usia subur (wus) tentang keputihan di Puskesmas Miri Sragen". Skripsi.

Sugiono, 2010, Metode Penelitian Kuantitatif Kualitatif DanR\&D, Alfabeta, Bandung.

Suparyanto, 2011 http://dr-suparyanto. blogspot.com/2011/10/wanita-usiasubur-wus.html (diunduh pada hari senin 28 januari 2014 pukul01.05).

Widyastuti, dkk .2009. Kesehatan Reproduksi, Yogyakarta : Fitrimaya.

Yeremia, C.2012. Gambaran Tingkat Pengetahuan Perawatan Area Genital pada Siswi SMP1 Taufiqurrahman Depok. Skripsi. 